\title{
Carbonic Acid Monohydrate
}

5 Evan H. Abramson ${ }^{1}$, Olivier Bollengier ${ }^{1}$, J. Michael Brown ${ }^{1}$, Baptiste Journaux ${ }^{1}$, Werner 6 Kaminsky $^{2}$, Anna Pakhomova ${ }^{3}$

$7{ }^{1}$ Department of Earth and Space Sciences, University of Washington, Seattle, Washington, 898195, USA

$9 \quad{ }^{2}$ Department of Chemistry, University of Washington, Seattle, Washington, 98195, USA

$10 \quad{ }^{3}$ Deutsches Elektronen-Synchrotron, Hamburg, 22607, Germany

\section{Abstract}

13 In the water-carbon dioxide system, above a pressure of $4.4 \mathrm{GPa}$, a crystalline phase consisting

14 of an adduct of the two substances can be observed to exist in equilibrium with the aqueous fluid.

15 The phase had been found to be triclinic, and its unit cell parameters determined, but the full 16 crystalline, and even molecular, structure remained undetermined. Here, we report new diamond-

17 anvil cell, x-ray diffraction data of a quality sufficient to allow us to propose a full structure. The

18 crystal exists in the $\mathrm{P} \overline{1}$ space group. Unit cell parameters (at $6.5 \mathrm{GPa}$ and $140^{\circ} \mathrm{C}$ ) are $19 a=5.8508(14) \AA, \quad b=6.557(5) \AA, \quad c=6.9513(6) \AA, \quad \alpha=88.59(2)^{\circ}, \quad \beta=79.597(13)^{\circ}, \quad$ and $20 \gamma=67.69(4)^{\circ}$. Direct solution for the heavy atoms (carbon and oxygen) revealed $\mathrm{CO}_{3}$ units, with 21 co-planar, but isolated, O units. Construction of a hydrogen network, in accordance with the 22 requirements of hydrogen bonding and with minimum allowed distances between non-bonded 
23 atoms, indicates that the phase consists of a monohydrate of carbonic acid $\left(\mathrm{H}_{2} \mathrm{CO}_{3} \cdot \mathrm{H}_{2} \mathrm{O}\right)$ with the

24 carbonic acid molecule in the cis-trans configuration. This is the first experimental determination

25 of the crystalline structure of a $\mathrm{H}_{2} \mathrm{CO}_{3}$ compound. The structure serves as a guide for ab initio

26 calculations that have until now explored only anhydrous $\mathrm{H}_{2} \mathrm{CO}_{3}$ solids, while validating

27 calculations that indicated that high pressures should stabilize $\mathrm{H}_{2} \mathrm{CO}_{3}$ in the solid state. If 4.4

$28 \mathrm{GPa}$ is the lowest pressure at which the phase is thermodynamically stable, this probably

29 precludes its existence in our solar system, although it may exist on larger, volatile-rich

30 exoplanets. If, however, its range of stability extends to lower pressures at lower temperatures

31 (which possibility has not yet been adequately explored) then it might have been be a stable form

32 of $\mathrm{CO}_{2}$ within the water-rich moons and dwarf planets prior to differentiation, and might still

33 exist on an undifferentiated Callisto.

35 Keywords: carbonic acid, $\mathrm{CO}_{2}$, hydrate, high-pressure, single-crystal X-ray diffraction, 36 exoplanets

\section{Introduction}

40 Water and carbon dioxide are ubiquitous compounds in the biological and geological sciences.

41 Their 1:1 adduct, carbonic acid $\left(\mathrm{H}_{2} \mathrm{CO}_{3}\right)$, and its two anions, bicarbonate $\left(\mathrm{HCO}_{3}{ }^{-}\right)$and carbonate

$42\left(\mathrm{CO}_{3}^{-2}\right)$, engage in an important set of reactions governing the solubility of $\mathrm{CO}_{2}$ and the $\mathrm{pH}$ of 43 systems critical to life and planetary processes. However, owing to unfavorable kinetics and 44 equilibrium constants at ambient conditions (Loerting et al. 2000), molecular carbonic acid has 
45 long eluded detailed experimental observation and, as described below, a crystalline structure

46 had not previously been determined. Recently, Wang et al. (2016) claimed to have observed the

47 formation of solid carbonic acid at high pressures, and Abramson et al. (2017) demonstrated that

48 the observed phase can exist in thermodynamic equilibrium with the aqueous fluid for pressures

49 beyond a quadruple point at $4.4 \mathrm{GPa}$. Preliminary X-ray results indicated that the new phase was

50 triclinic, but their quality did not allow a refinement of the crystal structure. Here, new X-ray

51 diffraction data of the high-pressure phase provide further insight into its structure. Despite

52 remaining uncertainties pertaining to the hydrogen network, the results confirm the presence of

$53 \mathrm{H}_{2} \mathrm{CO}_{3}$ molecules, and indicate that the crystal consists of a monohydrate of the acid. Our results

54 complete the initial experimental reports describing that phase, validate calculations which

55 indicated that high pressures should stabilize $\mathrm{H}_{2} \mathrm{CO}_{3}$ in the solid state, and offer a structure for a

$56 \quad \mathrm{H}_{2} \mathrm{CO}_{3}$ hydrate as a guide to further calculations.

\section{Prior Studies}

59 Over the past three decades, attempts to synthesize $\mathrm{H}_{2} \mathrm{CO}_{3}$ have led to the development of 60 numerous protocols divided among four main strategies. 1. The vacuum thermolysis of

61 carbonates led to the first reported synthesis of $\mathrm{H}_{2} \mathrm{CO}_{3}$, in the vapor phase; originally using

62 ammonium bicarbonate (Terlouw et al. 1987), the process was more recently accomplished with

63 di-tert-butyl carbonate (Reisenauer et al. 2014). 2. The irradiation of $\mathbf{C O}_{2}$ and $\mathbf{H}_{2} \mathbf{O}$ ices

64 produced the first $\mathrm{H}_{2} \mathrm{CO}_{3}$ solid; the initial experiment involved the proton irradiation of $\mathrm{CO}_{2}+$

$65 \mathrm{H}_{2} \mathrm{O}$ mixtures (Moore and Khanna 1991), but both UV photolysis (Gerakines et al. 2000; Wu et

66 al. 2003) and electron irradiation of the mixtures (Zheng and Kaiser 2007), as well as the proton 
67 irradiation of pure $\mathrm{CO}_{2}$ ice (Brucato et al. 1997; Garozzo et al. 2008) have also been successful.

68 3. The ionization of $\mathbf{C O}_{2}$ and $\mathbf{H}_{2} \mathrm{O}$ gases has been used to produce radicals for recombination

69 into $\mathrm{H}_{2} \mathrm{CO}_{3}$, either directly in the gas phase (Mori et al. 2009, 2011), or in the solid state by

70 deposition of $\mathrm{OH}$ radicals onto $\mathrm{CO}$ ice (Oba et al. 2010). 4. Finally, the protonation of

71 carbonates has been explored to produce $\mathrm{H}_{2} \mathrm{CO}_{3}$ in various states; short-lived aqueous $\mathrm{H}_{2} \mathrm{CO}_{3}$

72 was produced by reacting acids with $\mathrm{NaHCO}_{3}$ (Falcke and Eberle 1990; Lam et al. 2014),

$73 \mathrm{Na}_{2} \mathrm{CO}_{3}$ (Soli and Byrne 2002), or $\mathrm{DCO}_{3}^{-}$(Adamczyk et al. 2009); similarly, solid $\mathrm{H}_{2} \mathrm{CO}_{3}$ has

74 been synthesized through reactions in aqueous glasses, combining acids with $\mathrm{K}_{2} \mathrm{CO}_{3}$ or $\mathrm{KHCO}_{3}$

75 (Hage et al. 1995, 1996; Bernard et al. 2013), or particulate $\mathrm{CaCO}_{3}$ (Bernard et al. 2012); as well,

76 dry vapors of acids reacted with particulate $\mathrm{CaCO}_{3}$ (Al-Hosney and Grassian 2004, 2005; Al-

77 Hosney et al. 2005) have produced adsorbed $\mathrm{H}_{2} \mathrm{CO}_{3}$.

79 Following the first synthesis of solid $\mathrm{H}_{2} \mathrm{CO}_{3}$ (Moore and Khanna 1991), spectral analyses have

80 typically relied upon IR absorption and/or Raman spectroscopies. Direct confirmation of the

81 molecular composition has been confined to the gas phase syntheses, through neutralization-

82 reionization mass spectrometry (Terlouw et al. 1987) and microwave spectroscopy (Mori et al.

83 2009, 2011); X-ray diffraction patterns were reported for an amorphous solid (Winkel et al.

84 2007), however attempts to provide diffraction patterns of a crystallized sample were

85 inconclusive (Mitterdorfer et al. 2012; Bernard et al. 2013). These limitations gave room to the

86 belief, for two decades, that two different configurations of $\mathrm{H}_{2} \mathrm{CO}_{3}$ (then designated as $\alpha-\mathrm{H}_{2} \mathrm{CO}_{3}$

87 and $\beta-\mathrm{H}_{2} \mathrm{CO}_{3}$ ) had their own distinct amorphous, crystalline, and vapor phases preserved through

88 sublimation and condensation (Hage et al. 1995, 1996, 1998; Bernard et al. 2011, 2013); not until 
892014 was it discovered that only one of these phases $\left(\beta-\mathrm{H}_{2} \mathrm{CO}_{3}\right)$ pertained to $\mathrm{H}_{2} \mathrm{CO}_{3}$, while the

90 putative $\alpha-\mathrm{H}_{2} \mathrm{CO}_{3}$ actually consisted of the related monomethyl ester (Reisenauer et al. 2014).

91

92 Efforts to predict possible crystalline structure(s) for $\mathrm{H}_{2} \mathrm{CO}_{3}$ through ab initio calculations have

93 yielded a variety of solutions with differences in energy levels smaller than the uncertainties

94 (Winkel et al. 2007; Reddy et al. 2011). Simulations of the C-H-O system suggest that pressure

95 has a stabilizing effect on $\mathrm{H}_{2} \mathrm{CO}_{3}$, allowing several of its polymorphs, and a polymerized form, to

96 exist (at $0 \mathrm{~K}$ ) between $\sim 1$ and $\sim 300 \mathrm{GPa}$ (Saleh and Oganov 2016). In contrast to the

97 computational results, experimental studies of the $\mathrm{H}_{2} \mathrm{O}-\mathrm{CO}_{2}$ system under pressure had found

98 only two gas hydrates of $\mathrm{CO}_{2}$ (Sloan and Koh 2007; Tulk et al. 2014; Amos et al. 2017), both

99 existing only below $1 \mathrm{GPa}$ and decomposing into ices of their component molecules when

100 brought to higher pressures (Hirai et al. 2010; Bollengier et al. 2013; Tulk et al. 2014; Massani et

101 al. 2017). (The cryogenically prepared, amorphous carbonic acid, or its annealed form (Kohl et

102 al. 2009), may be stable at high pressures but, to our knowledge, this possibility has not been

103 tested. )

104

105 Recently, a new $\mathrm{CO}_{2}-\mathrm{H}_{2} \mathrm{O}$ compound was observed above $2.4 \mathrm{GPa}$ and asserted to be $\mathrm{H}_{2} \mathrm{CO}_{3}$

106 based on IR and Raman lines similar to those of the low pressure $\mathrm{H}_{2} \mathrm{CO}_{3}$ solid (Wang et al.

107 2016). Following this initial report, we (Abramson et al. 2017) demonstrated that this new phase

108 can exist in equilibrium with an aqueous fluid (starting from a quadruple point with ices

$109 \mathrm{H}_{2} \mathrm{O}(\mathrm{VII})$ and $\mathrm{CO}_{2}(\mathrm{I})$, at $4.4 \mathrm{GPa}$ and $165^{\circ} \mathrm{C}$ ), which allowed the growth of single crystals for

110 purposes of X-ray diffraction. However, non-hydrostatic strains in the crystal degraded the 
111 quality of the data, and only the lattice parameters of the triclinic crystal were determined; its full

112 structure, and chemical composition, remained unknown.

\section{Methodology}

$115 \mathrm{~A} \mathrm{CO}_{2}-\mathrm{H}_{2} \mathrm{O}$ mixture was loaded at the University of Washington into a Merrill-Bassett type 116 diamond-anvil cell (DAC) equipped with a $40 \mu \mathrm{m}$ thick rhenium gasket. The cell contents were 117 estimated at $30 \mathrm{~mol} \% \mathrm{CO}_{2}$ from visual observation of the loaded sample. Pressure was measured 118 to a precision of $0.1 \mathrm{GPa}$, using the Raman scattering from a chip of cubic boron nitride (cBN) 119 placed inside the sample chamber; excitation was provided by a $20 \mathrm{~mW}, 488 \mathrm{~nm}$ laser source. 120 Temperature was measured to an accuracy of $1 \mathrm{~K}$ through use of type $\mathrm{K}$ thermocouples. Further 121 details are given in Abramson et al. (2017). Single crystals were grown between pressures of 5 122 and $6 \mathrm{GPa}$ by slow cooling $\left(2{ }^{\circ} \mathrm{C} / \mathrm{min}\right)$ of the $\mathrm{H}_{2} \mathrm{O}-\mathrm{CO}_{2}$ fluid mixture after a few nuclei had been 123 isolated (figure 1); after crystallization, further cooling brought the pressure to $6.5 \mathrm{GPa}$.

125 The DAC was brought to the European Synchrotron Radiation Facility in Grenoble, France, for 126 single-crystal X-ray diffraction on beamline ID15b. Prior to data collection, the DAC was placed 127 in an external resistive heating system and brought to $140 \pm 2{ }^{\circ} \mathrm{C}$ to allow partial annealing of 128 residual strains; this produced an appreciable improvement in the sharpness of reflections. Data 129 were acquired using a wavelength of $0.4108 \AA$ and a beam diameter of $10 \mu \mathrm{m}$ FWHM. The 130 Bragg peaks from one crystal were collected on a MarCCD® flat panel detector (MAR555) 131 using the scan mode from $-28^{\circ}$ to $+28^{\circ}$ with an increment of $0.5^{\circ}$ and an exposure time of $1 \mathrm{~s}$. 132 The location of the collection spot (indicated in figure 1B) was chosen to provide a maximum 
133 thickness of single crystal, to avoid areas suspected to be subject to a greater non-hydrostatic

134 strain, and to limit shadowing from the gasket.

136 Data collection was $20.4 \%$ complete to $25^{\circ}$ in $\theta$. In total, 243 reflections were collected, covering

137 the indices $-6 \leq h \leq 6,-3 \leq k \leq 4$, and $-7 \leq l \leq 7$. Of these, 165 reflections were symmetry 138 independent with $\mathrm{R}_{\mathrm{int}}=0.0337$. Indexing and unit cell refinement indicated a primitive triclinic

139 lattice. The space group was found to be $\mathrm{P} \overline{1}$ (no. 2). The unit cell parameters closely match 140 those previously obtained at the Advanced Light Source in Berkeley (Abramson et al. 2017). 141 Angles $\left(\alpha=88.59(2)^{\circ}, \beta=79.60(1)^{\circ}\right.$, and $\left.\gamma=67.69(4)^{\circ}\right)$ agree within $0.1 \%$ while the new cell 142 dimensions $(a=5.851(1) \AA, b=6.557(5) \AA$, and $c=6.951(1) \AA)$ are $0.5 \%$ smaller, possibly due 143 to a slight compression resulting from the elevated temperature of the DAC (pressure was not 144 measured during data collection). The data were integrated and scaled using the CrysAlisPro 145 software (Rigaku Oxford Diffraction, 2015). Empirical absorption corrections were applied using 146 spherical harmonics, implemented in the SCALE3 ABSPACK scaling algorithm (Oxford 147 Diffraction, 2006).

\section{Structure Refinement}

150 A multi-step iterative approach based on plausible constraints was required to provide a full 151 structure for this triclinic crystal. After an initial model was obtained by direct solution, the 152 structure was completed by difference Fourier synthesis with SHELXL (Sheldrick 2015) using 153 scattering factors from Waasmair and Kirfel (1995). All non-hydrogen atoms were refined 154 anisotropically by full-matrix least-squares. The locations of hydrogen atoms were then 
155 determined based on the geometry of the carbon-oxygen structures and appropriate hydrogen-

156 bonding behavior. Crystallographic data are provided as supplementary material in a CIF file.

157 The process used to refine the structure is detailed below.

159 Initially, the direct solution produced a partial model with two $\mathrm{CO}_{3}$-resembling electron density

160 maxima per asymmetric unit of the space group. Two isolated oxygen atoms were found in the

161 vicinity of the $\mathrm{CO}_{3}$ groupings. The $\mathrm{CO}_{3}$ and $\mathrm{O}$ components are co-planar but separated by more

162 than $2 \AA$, precluding a covalent bond. To refine the $\mathrm{CO}_{3}$ geometries, their angles and bond

163 lengths were restrained to be as equivalent as possible while adequately fitting the data. In a

164 search for a shorter C-O distance in each grouping (as expected from a double bond), only one

165 out of nine possible permutations of one short and two long bonds per $\mathrm{CO}_{3}$ gave a satisfying R1,

166 and it was subsequently adopted. Since neither the bond lengths nor the angles were fixed, the

167 existence of one double bond in, and the planarity of, each $\mathrm{CO}_{3}$ was confirmed.

169 The last step in completing the structure consisted of placing hydrogen atoms in geometrically 170 ideal positions. The relative orientations of the $\mathrm{CO}_{3}$ were examined for possible H-bonds, for 171 which distance and angles matter (figure 2). Starting with the single-bonded oxygens of the $\mathrm{CO}_{3}$, 172 the closest receptor for the hydrogen of $\mathrm{O} 4$ is the double-bonded $\mathrm{O} 3 . \mathrm{O} 3$ is also at an appropriate 173 distance to act as a receptor for a hydrogen on 07 . The geometries of the water molecules $(\mathrm{O} 7$ 174 and O8) were then restrained with hydrogens set at $0.8 \AA$, resulting in a quasi-rigid model 175 allowed to rotate freely. The second hydrogen on $\mathrm{O} 7$ was assumed to bond with the closest out176 of-plane oxygen acceptor. With $\mathrm{O} 4$ and $\mathrm{O} 7$ set with $\mathrm{H}$-bonds to $\mathrm{O} 3$, the hydrogen on $\mathrm{O} 5$ was set 
177 towards $\mathrm{O} 8$, giving the $\mathrm{H}_{2} \mathrm{CO}_{3}$ molecule a cis-trans configuration. The hydrogen on $\mathrm{O} 1$ aligned 178 appropriately for hydrogen bonding without an added constraint. Once this satisfactory network 179 was complete, a few $\mathrm{H} \cdots \mathrm{H}$ distances fell in the $2.00-2.07 \AA$ range, slightly below the minimum 180 allowed distance of $2.1 \AA$, requiring an anti-bumping restraint. All hydrogens (with O-H bonds 181 restrained at $0.8 \AA$ ) could finally be assigned an appropriate orientation.

\section{Discussion}

184 The limited angular access available in a diamond-anvil cell, the low symmetry of the crystal, 185 and the small scattering cross-section of the hydrogen atoms all contributed to the challenge of 186 determining this structure. However, the direct method unambiguously determined the presence 187 of the $\mathrm{CO}_{3}$ and $\mathrm{O}$ components, yielding the formula with respect to $\mathrm{C}$ and $\mathrm{O}$. The distances 188 between neighboring components $\left(\mathrm{CO}_{3}\right.$ and $\left.\mathrm{O}\right)$ imply that they are isolated, precluding the 189 presence of more complex $\mathrm{C}-\mathrm{O}-\mathrm{H}$ molecules (notably the orthocarbonic acid $\mathrm{H}_{4} \mathrm{CO}_{4}$ of 190 equivalent bulk formula (Saleh and Oganov 2016), or dicarbonic acid $\mathrm{H}_{2} \mathrm{C}_{2} \mathrm{O}_{5}$ (Zeller et al. 2005;

191 Zhang et al. 2013)). Since only hydrogen atoms are available to bond with the $\mathrm{CO}_{3}$, molecular $192 \mathrm{H}_{2} \mathrm{CO}_{3}$ is required in the structure. Consequently, the final crystal formula $\left(\mathrm{CH}_{4} \mathrm{O}_{4}\right)$, the presence 193 of carbonic acid and its ratio to water, and the co-planar arrangement within the same (110) 194 planes of the oxygen and carbon of the carbonic acid, and oxygen of the water molecules, are 195 definitive conclusions of this work, independent of the subsequent interpretative steps used to 196 refine the hydrogen network. The final structure reached at the end of the last steps is fully

197 compatible with our dataset. As well, the calculated density of $2.194 \mathrm{~g} / \mathrm{cm}^{3}$ exceeds that of 
$198 \mathrm{H}_{2} \mathrm{O}$ (VII), $1.72 \mathrm{~g} / \mathrm{cm}^{3}$, consistent with the observation that the monohydrate will sink in the same 199 solution in which the latter will float (Abramson et al. 2017).

201 In our final structure, the $\mathrm{H}_{2} \mathrm{CO}_{3}$ and $\mathrm{H}_{2} \mathrm{O}$ molecules are organized on parallel, $\mathrm{H}$-bonded sheets

202 in (110) lattice planes (figure 3). Within each sheet, $\mathrm{H}_{2} \mathrm{CO}_{3}$ molecules form (hydrogen-bonded)

203 chains parallel to the c-axis with water providing in-plane hydrogen bonding between adjacent

204 chains. To our knowledge, ab initio calculations have only investigated pure $\mathrm{H}_{2} \mathrm{CO}_{3}$ structures so

205 far, limiting the relevance of direct comparisons with the present monohydrate; however, low-

206 pressure structures have indeed been said to favor chain- or sheet-like configurations (with the

207 planes of the individual $\mathrm{H}_{2} \mathrm{CO}_{3}$ molecules coincident with the crystal planes) (Reddy et al. 2011;

208 Saleh and Oganov 2016), as opposed to 3D networks for higher-pressure, polymerized structures

209 (Saleh and Oganov 2016).

210

211 The main uncertainty in our solution is in the determination of the hydrogen network. The

212 proximity of the $\mathrm{H}_{2} \mathrm{CO}_{3}$ molecules suggests $\mathrm{H}$ bonds exist between them; in turn, the relative

213 orientation of the molecules (i.e. the position of the $\mathrm{C}=\mathrm{O}$ bonds) suggests that the $\mathrm{H}_{2} \mathrm{CO}_{3}$ are in a

214 cis-trans configuration (as explained in the Structure Refinement section). Although the cis-cis

215 conformer has been identified as the most stable configuration for the isolated $\mathrm{H}_{2} \mathrm{CO}_{3}$ molecule,

216 for $\mathrm{H}$-bonded $\mathrm{H}_{2} \mathrm{CO}_{3}$ molecules, and for $\mathrm{H}_{2} \mathrm{CO}_{3}-\mathrm{H}_{2} \mathrm{O}$ complexes (see (Mori et al. 2009) and

217 references therein, and (Bernard et al. 2013)), the cis-trans conformer is considered a close

218 second (in comparison with the clearly less stable trans-trans), as well as a necessary step on the

219 decomposition (formation) pathway to (from) $\mathrm{CO}_{2}+\mathrm{H}_{2} \mathrm{O}$ (Mori et al. 2009). 


\section{Implications}

222 The present work provides the first characterization of the structure of a crystal containing the

$223 \mathrm{H}_{2} \mathrm{CO}_{3}$ molecule, which is additionally the only known example of a solid $\mathrm{H}_{2} \mathrm{CO}_{3}$ compound in

224 conditions of established thermodynamic equilibrium (i.e. a demonstrated, reversible transition).

225 The results validate calculations that indicate that high pressures can stabilize $\mathrm{H}_{2} \mathrm{CO}_{3}$ in the solid 226 state (Saleh and Oganov, 2016). The confirmation of the existence of a stable $\mathrm{H}_{2} \mathrm{CO}_{3}$ compound, 227 of its formation in the hydrated state, and of equilibrium with the aqueous fluid, may prove 228 useful both as a guide to future computational searches for stable structures within the $\mathrm{H}_{2} \mathrm{O}-\mathrm{CO}_{2}$ 229 system, and in stimulating further experimental exploration of this system.

231 In the absence of other $\mathrm{H}_{2} \mathrm{O}-\mathrm{CO}_{2}$ solids reported between $1.0 \mathrm{GPa}$ (the upper limit of the known $232 \mathrm{CO}_{2}$ gas hydrates) and $4.4 \mathrm{GPa}$ (the lower end of the proven stability field of the present 233 structure (Abramson et al. 2017)), the $\mathrm{H}_{2} \mathrm{CO}_{3}$ monohydrate may define the lower pressure 234 boundary of an extended domain of additional $\mathrm{H}_{2} \mathrm{O}-\mathrm{CO}_{2}$ compounds: the present monohydrate 235 was reportedly observed up to $25 \mathrm{GPa}$ (Wang et al. 2016), while simulations suggest a transition 236 around $\sim 300 \mathrm{GPa}$ from various polymorphs and polymers of $\mathrm{H}_{2} \mathrm{CO}_{3}$ to $\mathrm{H}_{4} \mathrm{CO}_{4}$ (Saleh and 237 Oganov, 2016). Alternatively, this (or other) carbonic acid hydrate(s) may exist between 1 and 238 4.4 GPa, but at temperatures below the solidus, where sluggish rates of solid-solid transitions 239 would have precluded their observation (note that in common hydrate-forming systems, e.g., $240 \mathrm{H}_{2} \mathrm{O}-\mathrm{MgSO}_{4}$ (Chou and Seal 2007), lower temperatures favor the formation of higher hydrates). 
242 Restricting our attention to the present $\mathrm{H}_{2} \mathrm{CO}_{3}$ monohydrate, if $4.4 \mathrm{GPa}$ is indeed the lower

243 pressure limit of its thermodynamic stability, this would likely preclude its existence in our solar

244 system. Ices within the (now differentiated) water-rich moons and dwarf planets of the outer

245 solar system do not achieve sufficiently high pressures, while in Earth, Neptune and Uranus,

246 temperatures at the requisite pressure are too high. Although radiolysis of mixed $\mathrm{H}_{2} \mathrm{O} / \mathrm{CO}_{2}$ ices,

247 or proton implantation into water ice, is believed to produce $\mathrm{H}_{2} \mathrm{CO}_{3}$ as a metastable molecule on

248 the surfaces of icy bodies, there has been no evidence that the monohydrate is formed in these

249 processes. If, however, lowering of temperature allows the hydrate to exist stably at lower

250 pressures (and this hasn't yet been explored), then it might have been a stable form of $\mathrm{CO}_{2}$ within

251 the water-rich moons and dwarf planets prior to differentiation, and might still exist on (a

252 partially differentiated) Callisto. Of course, considering the prevalence of $\mathrm{C}-\mathrm{H}-\mathrm{O}$ fluids in

253 planetary processes, the present $\mathrm{H}_{2} \mathrm{CO}_{3}$ monohydrate may be supposed to exist in some of the

254 (larger, volatile-rich) exoplanets of current interest.

\section{Acknowledgments}

257 This work was partially funded by NASA Solar System Workings grant 80NSSC17K0775 and 258 by the Icy Worlds node of NASA's Astrobiology Institute (08-NAI5-0021). Single-Crystal X259 Ray diffraction data were acquired at the ID15B beamline of the European Synchrotron Research 260 Facility, Grenoble, France. B. Journaux is being supported by the NASA Postdoctoral Program 261 and the NASA Astrobiology Institute. The authors would like to thank S. Petitgirard, I. Collings 262 and M. Hanfland for their scientific and technical support during the ID15b synchrotron beam 263 time. 


\section{References}

267 Abramson, E.H., Bollengier, O., and Brown, J.M. (2017) Water-carbon dioxide solid phase 268 equilibria at pressures above $4 \mathrm{GPa}$. Scientific Reports, 7, 821.

270 Adamczyk, K., Prémont-Schwarz M., Pines D., Pines E., and Nibbering E.T.J. (2009) Real-Time 271 Observation of Carbonic Acid Formation in Aqueous Solution. Science, 326, 1690-1694.

272

273 Amos, D.M., Donnelly, M.-E., Teeratchanan, P., Bull, C.L., Falenty, A., Kuhs, W.F., Hermann, 274 A., and Loveday, J.S. (2017) A Chiral Gas-Hydrate Structure Common to the Carbon 275 Dioxide-Water and Hydrogen-Water Systems. The Journal of Physical Chemistry Letters, 8, $276 \quad 4295-4299$.

277

278 Al-Hosney, H.A., and Grassian, V.H. (2004) Carbonic Acid: An Important Intermediate in the 279 Surface Chemistry of Calcium Carbonate. Journal of the American Chemical Society, 126, $280 \quad 8068-8069$.

282 Al-Hosney, H.A., and Grassian, V.H. (2005) Water, sulfur dioxide and nitric acid adsorption on 283 calcium carbonate: A transmission and ATR-FTIR study. Physical Chemistry Chemical $284 \quad$ Physics, 7, 1266-1276. 
Al-Hosney, H.A., Carlos-Cuellar, S., Baltrusaitis, J., and Grassian, V.H. (2005) Heterogeneous uptake and reactivity of formic acid on calcium carbonate particles: a Knudsen cell reactor, FTIR and SEM study. Physical Chemistry Chemical Physics, 7, 3587-3595.

Bernard, J., Seidl, M., Kohl, I., Liedl, K.R., Mayer, E., Gálvez, Ó., Grothe, H., and Loerting T. (2011) Spectroscopic Observation of Matrix-Isolated Carbonic Acid Trapped from the Gas Phase. Angewandte Chemie International Edition, 50, 1939-1943.

294 Bernard, J., Seidl, M., Mayer, E., and Loerting, T. (2012) Formation and Stability of Bulk 295 Carbonic Acid $\left(\mathrm{H}_{2} \mathrm{CO}_{3}\right)$ by Protonation of Tropospheric Calcite. ChemPhysChem, 13, 30873091.

Bernard, J., Huber, R.G., Liedl, K.R., Grothe, H., and Loerting, T. (2013) Matrix Isolation Studies of Carbonic Acid - The Vapor Phase above the $\beta$-Polymorph. Journal of the

301 American Chemical Society, 135, 7732-7737.

Bollengier, O., Choukroun, M., Grasset, O., Le Menn, E., Bellino, G., Morizet, Y., Bezacier, L., Oancea, A., Taffin, C., and Tobie G. (2013) Phase equilibria in the $\mathrm{H}_{2} \mathrm{O}-\mathrm{CO}_{2}$ system between 250-330 K and 0-1.7 GPa: Stability of the $\mathrm{CO}_{2}$ hydrates and the $\mathrm{H}_{2} \mathrm{O}$-ice VI at $\mathrm{CO}_{2}$ saturation. Geochimica et Cosmochimica Acta, 119, 332-339. 
Brucato, J.R., Palumbo, M.E., and Strazzulla G. (1997) Carbonic Acid by Ion Implantation in Water/Carbon Dioxide Ice Mixtures. Icarus, 125, 135-144.

310 Chou, I-M., and Seal, R.R. II (2007) Magnesium and calcium sulfate stabilities and the water 311 budget of Mars. Journal of Geophysical Research: Planets, 112, E11004.

313 Falcke, H., and Eberle, S.H. (1990) Raman spectroscopic identification of carbonic acid. Water 314 Research, 24, 685-688.

316 Garozzo, M., Fulvio, D., Gomis, O., Palumbo, M.E., and Strazzulla, G. (2008) H-implantation in $317 \quad \mathrm{SO}_{2}$ and $\mathrm{CO}_{2}$ ices. Planetary and Space Science, 56, 1300-1308.

319 Gerakines, P.A., Moore, M.H., and Hudson, R.L. (2000) Carbonic acid production in $\mathrm{H}_{2} \mathrm{O}: \mathrm{CO}_{2}$ ices. UV photolysis vs. proton bombardment. Astronomy and Astrophysics, 357, 793-800.

322 Hage, W., Hallbrucker, A., and Mayer, E. (1995) A Polymorph of Carbonic Acid and its Possible 323 Astrophysical Relevance. Journal of the Chemical Society, Faraday Transactions, 91, 28233242826.

326 Hage, W., Hallbrucker, A., and Mayer, E. (1996) Metastable intermediates from glassy solutions.

327 Part 4. FTIR spectra of $\beta$-carbonic acid and its ${ }^{2} \mathrm{H}$ and ${ }^{13} \mathrm{C}$ isotopic forms, isolated from 328 aqueous solution. Journal of the Chemical Society, Faraday Transactions, 92, 3197-3209. 
330 Hage, W., Liedl, K.R., Hallbrucker, A., and Mayer, E. (1998) Carbonic Acid in the Gas Phase $331 \quad$ and Its Astrophysical Relevance. Science, 279, 1332-1335.

333 Hirai, H., Komatsu, K., Honda, M., Kawamura, T., Yamamoto, Y., and Yagi, T. (2010) Phase 334 changes of $\mathrm{CO}_{2}$ hydrate under high pressure and low temperature. The Journal of Chemical $335 \quad$ Physics, 133, 124511.

337 Kohl, I., Winkel, K., Bauer, M., Liedl, K.R., Loerting, T., and Mayer, E. (2009) Raman 338 Spectroscopic Study of the Phase Transition of Amorphous to Crystalline $\beta$-Carbonic Acid. 339 Angewandte Chemie International Edition, 48, 2690-2694.

341 Lam, R.K., England, A.H., Sheardy, A.T., Shih, O., Smith, J.W., Rizzuto, A.M., Prendergast, D., 342 and Saykally, R.J. (2014) The hydration structure of aqueous carbonic acid from X-ray 343 absorption spectroscopy. Chemical Physics Letters, 614, 282-286.

345 Loerting, T., Tautermann, C., Kroemer, R.T., Kohl, I., Hallbrucker, A., Mayer, E., and Liedl, 346 K.R. (2000) On the Surprising Kinetic Stability of Carbonic Acid $\left(\mathrm{H}_{2} \mathrm{CO}_{3}\right)$. Angewandte 347 Chemie International Edition, 39, 891-894.

349 Massani, B., Mitterdorfer, C., and Loerting, T. (2017) Formation and decomposition of $\mathrm{CO}_{2^{-}}$ $350 \quad$ filled ice. The Journal of Chemical Physics, 147, 134503. 
352 Mitterdorfer, C., Bernard, J., Klauser, F. Winkel, K., Kohl, I., Liedl, K.R., Grothe, H., Mayer, E., 353 and Loerting, T. (2012) Local structural order in carbonic acid polymorphs: Raman and FT354 IR spectroscopy. Journal of Raman Spectroscopy, 43, 108-115.

356 Moore, M.H., and Khanna, R.K. (1991) Infrared and mass spectral studies of proton irradiated $357 \mathrm{H}_{2} \mathrm{O}+\mathrm{CO}_{2}$ ice: evidence for carbonic acid. Spectrochimica Acta, 47A, 255-262.

359 Mori, T., Suma, K., Sumiyoshi, Y., and Endo, Y. (2009) Spectroscopic detection of isolated 360 carbonic acid. The Journal of Chemical Physics, 130, 204308.

362 Mori, T., Suma, K., Sumiyoshi, Y., and Endo, Y. (2011) Spectroscopic detection of the most 363 stable carbonic acid, cis-cis $\mathrm{H}_{2} \mathrm{CO}_{3}$. The Journal of Chemical Physics, 134, 044319.

365 Oba, Y., Watanabe, N., Kouchi, A., Hama, T., and Pirronello, V. (2010) Formation of carbonic 366 acid $\left(\mathrm{H}_{2} \mathrm{CO}_{3}\right)$ by surface reactions of non-energetic $\mathrm{OH}$ radicals with $\mathrm{CO}$ molecules at low 367 temperatures. The Astrophysical Journal, 722, 1598-1606.

369 Oxford Diffraction (2006) ABSPACK (ver. 1.171.32.3), Oxford Diffraction Ltd, Abingdon, $370 \quad$ Oxfordshire, England. 
372 Reddy, S.K., Kulkarni, C.H., and Balasubramanian, S. (2011) Theoretical investigations of 373 candidate crystal structures for $\beta$-carbonic acid. The Journal of Chemical Physics, 134, $374 \quad 124511$.

375

376 Reisenauer, H.P., Wagner, J.P., and Schreiner, P.R. (2014) Gas-Phase Preparation of Carbonic 377 Acid and Its Monomethyl Ester. Angewandte Chemie International Edition, 53, 11766$378 \quad 11771$.

379

380 Rigaku Oxford Diffraction (2015) CrysAlisPro (ver. 1.171.38.43), Yarnton, England.

382 Saleh, G., and Oganov, A.R. (2016) Novel Stable Compounds in the C-H-O Ternary System at $383 \quad$ High Pressure. Scientific Reports, 6, 32486.

384

385 Sheldrick, G.M. (2015) Crystal structure refinement with SHELXL. Acta Crystallographica C, $386 \quad 71,3-8$.

387

388 Sloan, E.D. Jr., and Koh, C. (2007) Clathrate Hydrates of Natural Gases, Third Edition, 752 p.

389 CRC Press, Boca Raton.

390

391 Soli, A.L., and Byrne, R.H. (2002) $\mathrm{CO}_{2}$ system hydration and dehydration kinetics and the 392 equilibrium $\mathrm{CO}_{2} / \mathrm{H}_{2} \mathrm{CO}_{3}$ ratio in aqueous $\mathrm{NaCl}$ solution. Marine Chemistry, 78, 65-73. 393 
394 Terlouw, J.K., Lebrilla, C.B., and Schwarz, H. (1987) Thermolysis of $\mathrm{NH}_{4} \mathrm{HCO}_{3}-$ A Simple

395 Route to the Formation of Free Carbonic Acid $\left(\mathrm{H}_{2} \mathrm{CO}_{3}\right)$ in the Gas Phase. Angewandte 396 Chemie International Edition, 26, 354-355.

398 Tulk, C.A., Machida, S., Klug, D.D., Lu, H., Guthrie, M., and Molaison, J.J. (2014) The 399 structure of $\mathrm{CO}_{2}$ hydrate between 0.7 and $1.0 \mathrm{GPa}$. The Journal of Chemical Physics, 141, $400 \quad 174503$.

401

402 Wang, H., Zeuschner, J., Eremets, M., Troyan, I., and Williams, J. (2016) Stable solid and 403 aqueous $\mathrm{H}_{2} \mathrm{CO}_{3}$ from $\mathrm{CO}_{2}$ and $\mathrm{H}_{2} \mathrm{O}$ at high pressure and high temperature. Scientific Reports, $404 \quad 6,19902$.

405

406 Waasmaier, D., and Kirfel, A. (1995) New analytical scattering-factor functions for free atoms 407 and ions. Acta Crystallographica A, 51, 416-431.

408

409 Winkel, K., Hage, W., Loerting, T., Price, S.L., and Mayer, E. (2007) Carbonic Acid: From 410 Polyamorphism to Polymorphism. Journal of the American Chemical Society, 129, 13863$411 \quad 13871$.

412

413 Wu, C.Y.R., Judge, D.L., Cheng, B.-M., Yih, T.-S., Lee, C.S., and Ip, W.H. (2003) Extreme 414 ultraviolet photolysis of $\mathrm{CO}_{2}-\mathrm{H}_{2} \mathrm{O}$ mixed ices at $10 \mathrm{~K}$. Journal of Geophysical Research: $415 \quad$ Planets, 108, 5032. 
417 Zeller, K.-P., Schuler, P., and Haiss, P. (2005) The Hidden Equilibrium in Aqueous Sodium 418 Carbonate Solutions - Evidence for the Formation of the Dicarbonate Anion. European 419 Journal of Inorganic Chemistry, 2005, 168-172.

420

421 Zhang, L., Huang, X., Qin, C., Brinkman, K., Gong, Y., Wang, S., and Huang, K. (2013) First 422 spectroscopic identification of pyrocarbonate for high $\mathrm{CO}_{2}$ flux membranes containing highly 423 interconnected three dimensional ionic channels. Physical Chemistry Chemical Physics, 15, $424 \quad$ 13147-13152.

425

426 Zheng, W., and Kaiser, R.I. (2007) On the formation of carbonic acid $\left(\mathrm{H}_{2} \mathrm{CO}_{3}\right)$ in solar system 427 ices. Chemical Physics Letters, 450, 55-60. 
431 Figure 1. (a) Photomicrograph of the pressure chamber during growth of euhedral crystals from 432 the fluid phase. (b) After cooling to room temperature. The small, dark cross-hairs indicate the 433 approximate location of X-ray impingement during data collection.

434 Figure 2. ORTEP of the structure with thermal ellipsoids at the 50\% probability level.

435 Figure 3. (a) Illustration of the layered structure of the crystal with the (110) sheets. The box of 436 solid, black lines represents the unit cell dimensions. (b) View perpendicular to a (110) sheet, 437 showing the cis-trans configuration of the carbonic acid molecules and hydrogen-bonded chains 438 of $\mathrm{H}_{2} \mathrm{CO}_{3}$ along the c-axis. $\mathrm{C}, \mathrm{O}$ and $\mathrm{H}$ atoms are depicted as black, red and pink spheres, 439 respectively. 


\section{Figure 1}
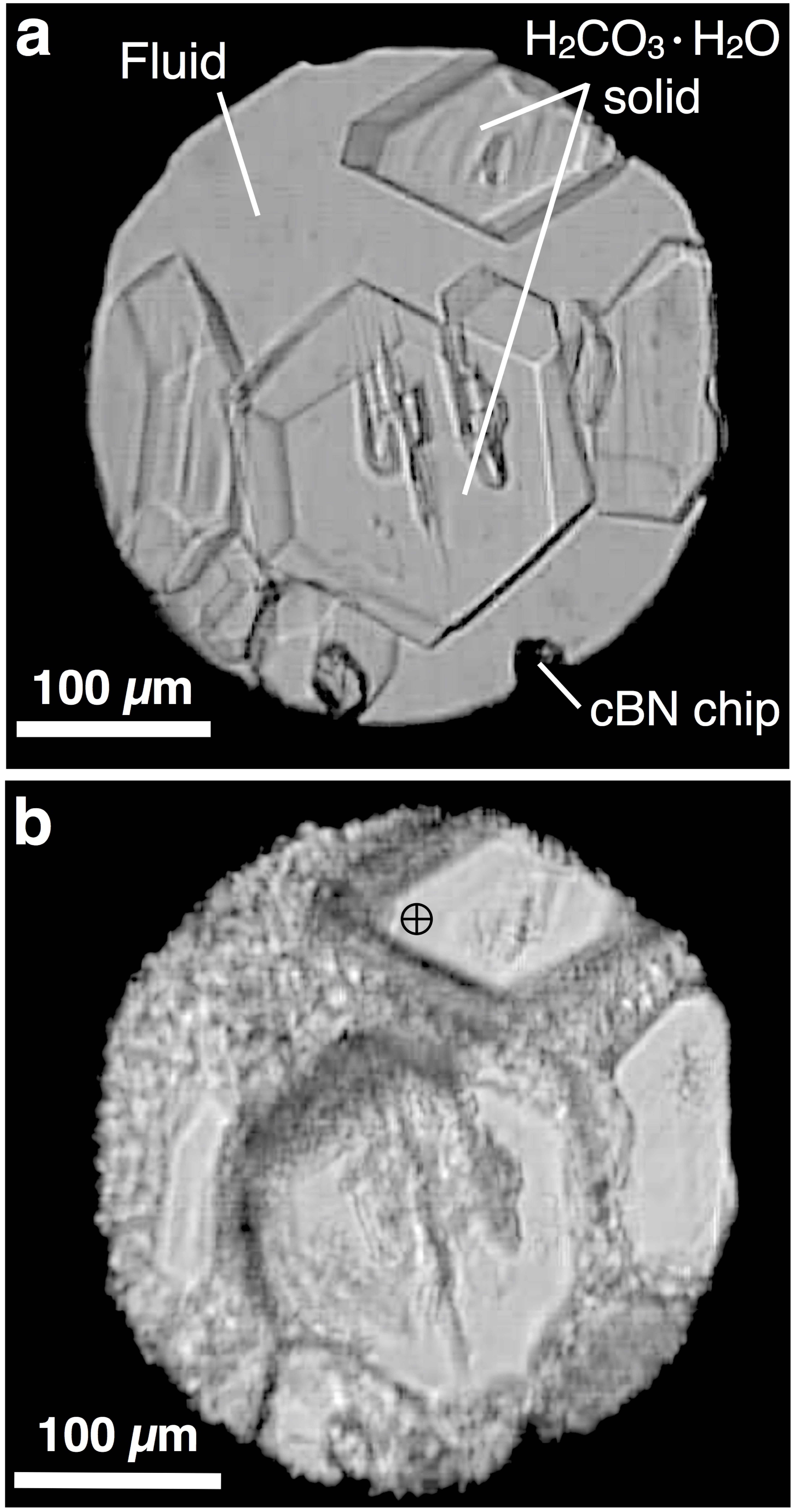


\section{Figure 2}

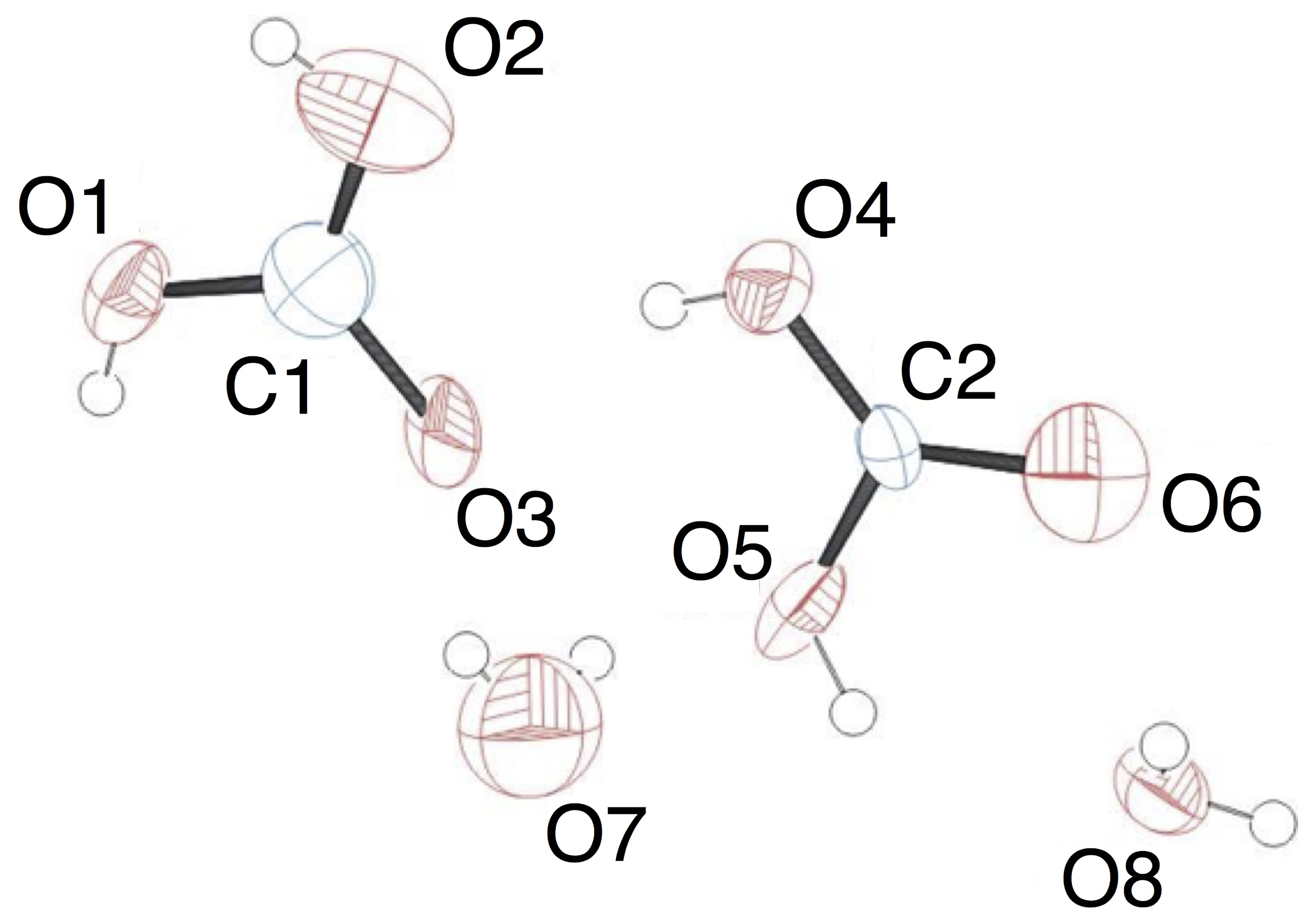




\section{Figure 3}

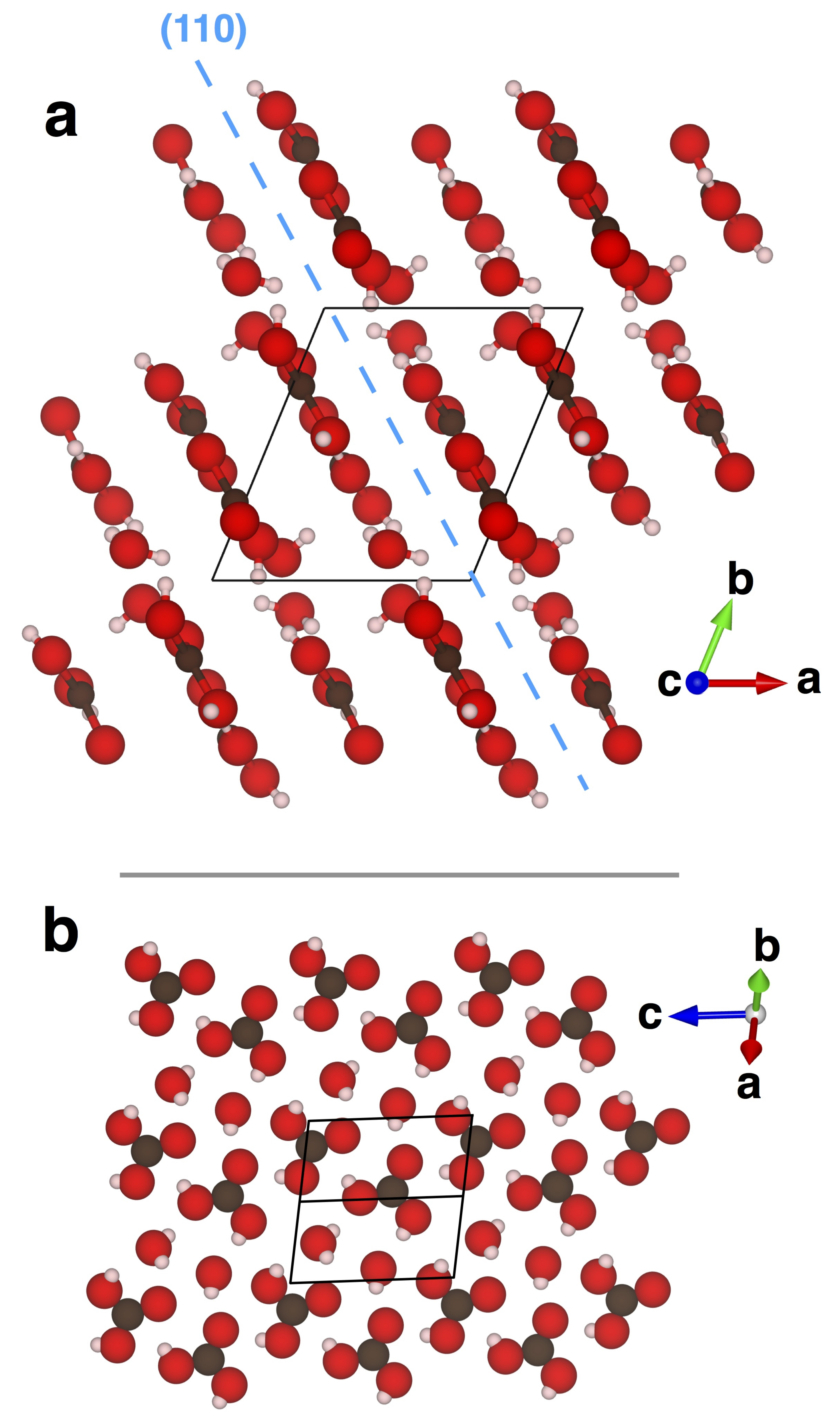

